\title{
The Inclusive Engineering Consortium Stakeholders Workshop
}

\section{Dr. John C. Kelly, North Carolina A\&T State University}

Dr. John C. Kelly, Jr. is an associate professor in the Department of Electrical and Computer Engineering at North Carolina A\&T State University. He received his Ph.D. in Electrical Engineering from the University of Delaware. Dr. Kelly's research interests include hardware security in cyber-physical systems and embedded systems security. He also contributes to research on engineering education, enhanced retention of underrepresented minorities in engineering, and hands-on learning techniques.

\section{Dr. Mohamed F. Chouikha, Prairie View A\&M University}

Dr. Mohamed Chouikha is a Executive Professor in the Department of Electrical and Computer Engineering at Prairie View A\&M University. He received his M.S. and PhD. in Electrical Engineering from the University of Colorado-Boulder. Dr. Chouikha research interests include hardware security, cybersecurity machine learning and multimedia signal processing and communications for secure networks, among other areas. He also focuses on enhancing recruitment and retention of underrepresented minorities in the STEM areas in general, engineering in particular.

\section{Dr. Craig J. Scott, Morgan State University}

Dr. Craig J. Scott received his Ph.D. and B.S. in Electrical Engineering from Howard University and a M.S. in Electrical Engineering from Cornell University. He is currently serving as professor and Interim Dean for the Clarence Mitchell Jr. School of Engineering. Morgan State University at one of the nation's preeminent public urban research institutions in the Clarence Mitchell Jr. School of Engineering at Morgan State University, Baltimore, Maryland. His career spans over twenty-eight years of progressive scholarly experience in such areas as research administration/ implementation, pedagogical innovation, international collaboration, strategic planning, promoting community engagement and academic program development. He instructs courses in computer vision, computer graphics, electromagnetics and characterization of semiconductor materials.

\section{Dr. Kenneth A Connor, Rensselaer Polytechnic Institute}

Kenneth Connor is an emeritus professor in the Department of Electrical, Computer, and Systems Engineering (ECSE) at Rensselaer Polytechnic Institute (RPI) where he taught courses on electromagnetics, electronics and instrumentation, plasma physics, electric power, and general engineering. His research involves plasma physics, electromagnetics, photonics, biomedical sensors, engineering education, diversity in the engineering workforce, and technology enhanced learning. He learned problem solving from his father (who ran a gray iron foundry), his mother (a nurse) and grandparents (dairy farmers). He has had the great good fortune to always work with amazing people, most recently the members and leadership of the Inclusive Engineering Consortium (IEC) from HBCU and HSI ECE programs and the faculty, staff and students of the Lighting Enabled Systems and Applications (LESA) ERC, where he was Education Director until his retirement in 2018. He was RPI ECSE Department Head from 2001 to 2008 and served on the board of the ECE Department Heads Association (ECEDHA) from 2003 to 2008. He is a Life Fellow of the IEEE.

\section{Dr. Demetris Geddis, Hampton University}

Demetris L. Geddis is an associate professor and Chair of Electrical and Computer Engineering at Hampton University. He has extensive research experience in the areas of Integrated optoelectronics, Optics, Microelectronics, and Electromagnetics. He has worked as a Research and Design Engineer at Motorola and Bell laboratories. Also, he worked at NASA Langley Research Center as a NASA faculty fellow for the Nondestructive Evaluation Sciences Branch where he performed research in the area of optical fiber sensing for real time health monitoring of aerospace vehicles. In addition, Prof. Geddis was a Research Engineer at the Georgia Tech Research Institute where he fabricated scalable multiplexed ion traps for 
quantum computing applications. Current research interests and publications are in the areas of Photonics, Optoelectronics, Microelectronics, Heterogeneous thin film integration, single-fiber bi-directional communications, optical sensing, and ring lasers. Before joining Hampton University in 2017, Prof. Geddis was a faculty member at Norfolk State University for 12 years.

\section{Dr. Mandoye Ndoye, Tuskegee University}

Mandoye Ndoye received the B.S.E.E. degree from the Rensselear Polytechnic Institute, Troy, NY, in 2002, the MS degree in Mathematics and the Ph.D. degree in electrical and computer engineering from Purdue University, West Lafayette, IN, in 2010. After completing his Ph.D. studies, he joined the Center of Applied Scientific Computing, Lawrence Livermore National Laboratory, as a Research Staff Member. From 2012 to 2014, he was a Research Associate at Howard University. Since 2014, he has been an Assistant Professor with the Department of Electrical Engineering, Tuskegee University, Tuskegee, AL. His research interests center on signal/image processing, sensor data analytics, intelligent infrastructure systems and power systems optimization.

\section{Dr. Shiny Abraham, Seattle University}

Shiny Abraham is an Assistant Professor of Electrical and Computer Engineering at Seattle University. She received the B.E. degree in Telecommunication Engineering from Visveswaraiah Technological University (VTU), India in 2007 and Ph.D. from Old Dominion University, Norfolk, VA in 2012. Her research interests span the areas of Wireless Communication, Internet of Things (IoT), Optimization using Game Theory, and Engineering Education Research. She is a member of the IEEE and ASEE, a technical program committee member for IEEE Globecom, ICC, ICCCN and VTC conferences, and a reviewer for several international journals and conferences.

\section{Prof. Miguel Velez-Reyes P.E., University of Texas at El Paso}

Miguel Velez-Reyes received the B.S.E.E. degree from the University of Puerto Rico at Mayaguez (UPRM), in 1985, and the M.S. and Ph.D. degrees from the Massachusetts Institute of Technology, Cambridge, in 1988, and 1992, respectively. He was with the University of Puerto Rico at Mayaguez 1992-2012. Since August 2012, he is Professor and Chair of the Electrical and Computer Engineering Department at the University of Texas at El Paso. He has held Faculty Internship Positions with AT\&T Bell Laboratories, Air Force Research Laboratories, and the NASA Goddard Space Flight Center. His teaching and research interests are in signal and sensor analytics, information extraction from dynamic systems using remote or minimally intrusive sensing, hyperspectral remote sensing, and data-driven science and engineering. $\mathrm{He}$ has over 160 publications in journals and conference proceedings and has contributed to three books. He was the Director of the Institute for Research in Integrative Systems and Engineering (IRISE) at UPRM and Associate Director of the NSF Center for Subsurface Sensing and Imaging Systems a NSF Engineering Research Center led by Northeastern University. He was director for the UPRM Tropical Center for Earth and Space Studies, a NASA University Research Center. In 1997, Dr. Velez-Reyes was one of 60 recipients from across the United States and its territories of the Presidential Early Career Award for Scientists and Engineers from the White House. In 2005, Dr. Velez-Reyes was inducted in the Academy of Arts and Sciences of Puerto Rico. In 2010, Dr. Velez-Reyes was elected Fellow of SPIE for his contributions to hyperspectral image processing. He is the chair of the SPIE Conference on Algorithms and Technologies for Multispectral, Hyperspectral, and Ultraspectral Imagery. He is a senior member of the IEEE where he has held many posts such as president of the IEEE Western Puerto Rico Section, and Latin America representative to the IEEE PELS AdCom. He is a member of the Tau Beta Pi, Sigma Xi, and Phi Kappa Phi honor societies.

\section{Dr. Saleh Zein-Sabatto, Tennessee State University}

Saleh Zein-Sabatto: Dr. Zein-Sabatto has a strong commitment for teaching and research. His area of competency includes teaching and conducting theoretical and experimental research in intelligent control systems, adaptive control systems, manipulator controls, intelligent mobile robotic behaviors, cooperative multiple robotic systems, fault diagnostics systems, neural network and fuzzy logic applications to robotics and control. Dr. Zein-Sabatto has been teaching engineering design for over fifteen years. 


\section{Dr. Raziq Yaqub, AAMU}

Dr. Raziq Yaqub is an Associate Professor in the Department of Electrical Engineering and Computer Science, Alabama A\&M University (AAMU), USA. He earned a Ph.D. in Wireless Communication from Keio University, Japan, and an MBA in Marketing from Fairleigh Dickenson University, New Jersey, USA.

$\mathrm{He}$ is an inventor of numerous technologies in Cybersecurity of Financial Technologies and Air Vehicles, Wireless Communications, Smart Grid, and Connected Electric Vehicles. He filed more than 50 patents. In 2009, he received Innovator Award and in 2014, "Inventor of the Year Award" both from the Governor of the State of New Jersey, USA, and thus he got inducted in Inventors Hall of Fame, New Jersey. In 2019, he received an award of "Excellence in Scholarship and Research" from the President, AAMU, an award of "Innovator Young Faculty" from the Dean, CETPS, Alabama A\&M University, and an award of "Outstanding Educator" from IEEE.

He remained an Executive Director of Toshiba America Research, New Jersey, USA, to lead 4G/LTE, Department head of NIKSUN University, Princeton, New Jersey, to lead Cybersecurity, and Director of Global R\&D of Tecvox, Huntsville, AL, USA, to lead wireless charger and media hubs for the automotive industry. He also remained Sr. Consultant to the State of New Jersey, a spokesperson of Department of Homeland Security, in 3GPP on behalf USA", an invited Researcher in NASA Research Center, Cleveland, Ohio, an inventor for Wells Fargo, and an Associate Professor at the University of Tennessee, Chattanooga.

He also remained Chairman Academic Standards Committee, Chairman, and contributor in standards organizations such as 3GPP, IEEE, WiMAX, MWIF, OMA, Chair IEEE Membership Development, Vice Chairman of IEEE Southeast Conference 2019 that was attended by 1100 attendees, organizer of numerous international conferences, Invited/Keynote speaker/Panel Moderator/Resource Person in international events. He is a Senior Member of IEEE. 


\title{
The Inclusive Engineering Consortium
}

\begin{abstract}
Over the last 7 years, a collaboration of 13 HBCU Electrical and Computer Engineering (ECE) programs has been working together to implement Experiment Centric Pedagogy to improve their student learning experience. The lessons learned and best practices of that effort have encouraged the 13 partners to expand the scope of their collaboration to address the full learning and working experience of students, faculty and staff and to expand the group to include other minority serving institutions with ECE and similar programs. With the assistance of the Electrical and Computer Engineering Department Heads Association, the group has created a new organization, the Inclusive Engineering Consortium, consisting of a core group of collaborators and a second, much larger group of affiliated members from other universities, industry and professional societies. The first face-to-face meeting of the new organization was held in July, 2019. Participants included representative from member institutions and industrial partners. This paper will provide a summary of the outcomes from the workshop's sessions: Broad Appeal Programs; Investment in Leaders/Future Leaders; Strategic Connections; Infrastructure; and Building IEC.
\end{abstract}

\subsection{History of and First Steps in Building the New Inclusive Engineering Consortium}

The Inclusive Engineering Consortium (IEC) is a novel collaboration among the 15 ABET accredited Electrical and Computer Engineering (ECE) programs at the nation's Historically Black Colleges and Universities (HBCU) and 2 Hispanic Serving Institutions (HSI). The 15 HBCUs include the 13 departments (Alabama A\&M University, Florida A\&M University, Hampton University, Howard University, Jackson State University, Morgan State University, Norfolk State University, North Carolina A\&T State University, Prairie View A\&M University, University of Maryland at Eastern Shore, Southern University, Tennessee State University, and Tuskegee University) who participated in the NSF Experiment Centric Pedagogy project (see below) plus Virginia State University and the University of the District of Columbia. The 2 HSIs are The University of Texas at El Paso and Ana G. Méndez University, Gurabo Campus.

It is a well-recognized fact that it is challenging for Minority Serving Institutions (MSI) to individually conduct large-scale research due to limited resources. SWOT analyses conducted among consortium members in recent workshops have clearly supported this claim (see section "Recent IEC Activities"). A single consortium institution is not as competitive as a collaborative effort among multiple institutions, where the strengths of each institution can be combined to address a meaningful educational or technical research challenge. Hence, over the past several years, IEC member institutions have developed a culture of collaboration at different levels, with effective methods of implementation. We believe this collaboration can be leveraged and moved to the next level to provide higher capacity building at each of the consortium members. The hypothesis is that there are windows of opportunity open through establishment of research and educational collaborations between IEC members and with R1 research-intensive institutions. This is especially true since IEC member institutions serve a unique population of minority students.

The reality is, it is challenging for small to mid-sized education programs, especially those at minority-serving institutions, to establish mutually beneficial relationships with programs at larger 


\section{The Inclusive Engineering Consortium}

R1 institutions. So far, most research collaborations with strong R1 institutions have involved only one or two MSIs playing a peripheral role and rarely engaged at the start of the effort. Similarly, interactions with government and industry are often focused on hiring students in those strong research-based R1 programs.

The future of any educational institution depends on the quality of its educational programs and clear pathways to future professional careers for its students. In the past decade, the engineering disciplines in general, and ECE in particular, have been experiencing huge transformations with fast-emerging new disciplinary areas. New technology areas range from quantum computing to machine learning, cyber-physical systems, internet of things (IOT), industrial internet of things (IIOT), etc. It is becoming a challenge for small educational institutions such as some IEC members to reflect new technology areas in their educational offerings, as well as take advantage of new trends in engineering education for their students. One way to address such challenges is to team up with peer MSIs or larger R1 institutions in mutually beneficial collaborative research and educational programs.

IEC is developing the infrastructure and programs to facilitate collaborations between faculty, students and staff in its member departments, based largely on lessons learned from the successful ECP educational program. It is also addressing how best to build a different type of team with R1 schools, industry, and other external constituencies. For each type of partner, a process is being defined and tools, such as evaluation rubrics to assess the quality and productivity of collaborations, are being addressed. A pilot process and rubric now exist that will be further refined what works and what does not in both internal and external collaborations.

\section{Experimental Centric Based Engineering Curriculum for HBCUs}

In Fall 2013, Howard University, in collaboration with the 12 HBCUs listed above, received funding for the NSF ECP project. The project had the significant outcome to create an "HBCU Engineering Network" that is focused on the development, implementation, and expansion of an Experimental Centric-based instructional Pedagogy in engineering curricula used in these HBCUs.

The project started during the 2013-2014 academic year by implementing a hands-on approach that introduced concepts related to circuit analysis and experiment design to selected ECE. By the end of 2016 over 100 curriculum modules were developed and used in classes at all undergraduate levels from introductory courses to senior capstone design and in undergraduate research projects such as REU and RET programs.

The project successfully demonstrated that an experimental centric pedagogy combined with hands-on educational technology stimulates student interest in the STEM area, promotes content acquisition, and problem solving, and retention. Hands-on activities were shown to be successful across a variety of instructional settings and EE topics. The momentum that the project has is remarkable. By the end of the project practically all the minority students at the 13 institutions (which represent over 35\% of the entire population of the African-Americans in engineering in the United States) were exposed to multiple experiences with mobile boards. In the 13 


\section{The Inclusive Engineering Consortium}

institutions, personal instrumentation either completely replaced or complemented the traditional laboratory experiments which were usually based on traditional benchtop equipment. The handson activities at all the institutions were evaluated by an external assessment group and the results were presented at multiple American Society for Engineering Education Conferences.

The project has engaged a large fraction of the faculty at the partner institutions. In the original 13 HBCUs, there are 135 faculty and 2950 students. During the ECP project, 45 faculty participated by developing and implementing course modules, regularly attending both online and in-person meetings. Since expanding to 17 schools, there are now 160 faculty and 3800 students and faculty participation has risen to 70 . There have been 43 authors on publications. This high level of participation occurred while the focus of the collaboration has been mostly on ECP as implemented in circuits and electronics courses. Based on discussions held at HBCU Dean's meetings, this exceptional level of collective effort has not occurred previously.

The success of the HBCU ECP project led the group to consider whether or not the scope of the collaboration could be expanded to include a broader range of topics and participants. For the last two years, the group has been reflecting on lessons there to be learned from this experience. Both formal processes (e.g., SWOT analysis, surveys) and informal processes (e.g., brainstorming and random discussions), in person and online, have been utilized. What follows is a brief summary of what has been learned so far.

- First and foremost, the project succeeded because many schools worked together as one to collectively implement ECP using personal instrumentation at all 13 schools.

- Experienced faculty trained instructors at schools new to personal instrumentation at both face-to-face workshops and regular online meetings.

- Participants engaged in effective, regular, nearly weekly online meetings.

- Common assessment tools were developed and implemented with guidance from an experienced team from UAlbany.

- Activities and accomplishments were collectively documented through regular participation in ASEE meetings.

- The project actively involved both department heads and teaching faculty.

- New connections were developed with outside schools and industry.

- Collaborations were expanded to include technical research.

- Other MSIs were added including HBCUs (UDC and VSU) and HSIs (UTEP, UAGMTurabo)

- Overall, a very productive network of participants was developed based on mutual respect, trust and confidence in the group's ability to collectively produce high quality work.

The group encountered some significant issues (speed bumps, barriers ...) that impeded its ability to achieve its goals as quickly and effectively as it had hoped.

- The support infrastructure at participating schools is not presently adequate to facilitate collaborations. Contracts and grants offices generally could not respond quickly and 


\section{The Inclusive Engineering Consortium}

reliably. It was also not possible to create and maintain an effective external web presence. Internally, content was quite productively shared, but required a lot of personal intervention using email, phone calls and face-to-face communication.

- Experience doing collaborative research is limited both among ECP participant schools and with R1 institutions. The number of such experiences is small and, for R1 collaborations, the participant schools are almost always added to teams late in the game after the project is nearly fully developed. Several schools have experience in ERCs, but only one has ever been the lead. Research capabilities in particular areas are not significant at most institutions but, collectively, a critical size can be realized by combining faculty/labs/students/staff/resources from several schools.

- Faculty at participating institutions have very large teaching and advising responsibilities and are given inadequate opportunities to learn how to be leaders and how to build research programs.

- The ECE programs that make up the collaboration are generally under-resourced.

The experiences of the 13+ HBCU ECE programs who made ECP work are consistent with what has been observed by researchers who study Team Science. There are two National Academy Reports that do an excellent job of summarizing the Science of Team Science Enhancing the Effectiveness of Team Science identifies 'Seven Key Features That Create Challenges for Team Science' that have impacted the ability of ECP participants to fully contribute to collaborations with R1 partners: 1) High Diversity of Membership; 2) Deep Knowledge Integration; 3) Large Size; 4) Goal Misalignment with Other Teams; 5) Permeable Boundaries; 6) Geographic Dispersion; and 7) High Task Interdependence. Two conclusions from Team Science research that connect particularly well with the experience of the ECP collaboration:

- 'Team professional development training improves team processes and outcomes; and

- Geographically dispersed science teams and groups face more challenges in communicating and developing trust than do face-to-face teams and groups.'

One of the references from the Team Science report that resonates particularly well with the mixed methods assessment methodology used in the ECP program is K. C. Wooten et al in which Table 1 lists the type of outcome, process and developmental evaluation that the ECP evaluator team implemented with similar success.

Based on what has been learned from this reflection, a series of working hypotheses have been developed on what the group should do if it hopes to expand the limited set of goals of the ECP project to address all aspects of the ECE enterprise at MSIs and elsewhere.

- A new organization is necessary to handle funding and general infrastructure.

- If the collective group of schools can function as a virtual super department, it will be possible to collaborate with outside schools and other institutions as equals.

- Infrastructure will include leadership training and other professional development through workshops and mentoring, especially for writing proposals and doing collaborative research. 


\section{The Inclusive Engineering Consortium}

- Sustainability requires the existence of a formal entity. To this end, the IEC was created, which, being a new organization, requires continuous development. IEC can provide all of the above through effective fund-raising, especially with industry and foundations.

\section{Inclusive Engineering Consortium}

In March of 2017, conversations and meetings began regarding the future of the ECP collaboration. An organization separate from any one university was needed to sustain the gains experienced during the ECP period and support the future growth of the group. There needed to be an entity that behaves like a large virtual department composed of the faculty, staff, and students of the member departments. This virtual department has access to opportunities unavailable to any one department. This distinction is important. The new organization does not compete with the departments, but rather magnifies the departments. The ECP group met at the 2018 ECEDHA annual meeting, held an additional workshop in Alexandria, VA in June, 2018 and continued regular weekly online meetings. Based on these conversations and meetings, and with the guidance and support of ECEDHA leadership, a 501(c)(3) corporation called the Inclusive Engineering Consortium, was created early in 2019. The first IEC workshop was held in July 2019, with assistance and meeting facilities provided by Intel, as described in the following section. All faceto-face meetings were made possible by support from NSF, either through the ECP grant funds or workshop grants. Support was also provided by individual partner institutions.

\section{Summary of Recent IEC Activities}

The IEC Stakeholders Workshop was held at Intel headquarters in Tigard, OR, 14-15 July 2019. At this workshop, IEC members and industrial partners began the creation of the organizational support structure and identified the initial activities necessary to realize IEC's grand vision of becoming a virtual super department with broadly based strengths in education, scholarship and service. Prior to the workshop, there was an online meeting on 26 June to brief participants on IEC status, to provide an overview of the workshop and to assign tasks to be completed prior to the meeting. Participants were asked to complete a personal SWOT and to provide one or two slides on their research background and interests. Workshop sessions focused on developing consensus on the short- and long-term tasks for IEC members and partners. After the workshop, there was a second online meeting on 24 September (also the first regular monthly IEC meeting of the fall semester) to provide an update on IEC activities, particularly the results from the two working groups on barriers for students and faculty (see below). There was also a discussion of papers to submit to ASEE.

The workshop began on the evening of the $14^{\text {th }}$ with a working dinner where status updates were presented on collaborative activities, IEC and pre-workshop activities. Workshop tasks were also reviewed. On the $15^{\text {th }}$, there was a full day of topical sessions culminating in a second working dinner to address strategies and summarize the list of immediate tasks. Session 1: Broad Appeal Programs - building a strong foundation for collaborative research within the consortium. Session 2: Leadership and Professional Development - how best to help students, staff, faculty and leaders at all levels prepare for successful careers. Session 3: Strategic Connections - elements of ideal, mutually beneficial strategic partnerships in which the super department of MSI ECE programs functions as the equal of strong R1 departments. Session 4: Infrastructure - infrastructure necessary to position IEC for future success

Key tasks were identified, with a strong emphasis on short-term goals to get IEC established. Individuals were also designated to lead these activities. 


\section{The Inclusive Engineering Consortium}

- A regular IEC newsletter to share information with members and potential outside collaborators on member highlights, events, industrial perspectives, professional development, etc.

- An IEC website as a portal to member information on their local websites. Key contacts at each institution were also to be. In addition to connecting to local websites, the IEC website is to include information on

- Research topics of interest to IEC members

- Specialized facilities and major equipment, where applicable, associated with current research

- Grant proposal and review activity

- Continue to use SWOT analyses to address the needs of faculty, faculty and staff at IEC member institutions, the interface between IEC and outside collaborators (R1 universities, industry, foundations, NGOs, professional societies ...). The immediate follow up task is to identify barriers faced by IEC students and faculty.

- Support structure and professional development for proposal writing. This is presently being addressed by working with successful group proposal teams from within IEC. Specifically, Kofi Nyarko and Kemi Ladeji-Osias, both from Morgan State, have made presentations on best practices during IEC monthly meetings. Kofi leads the $\mathrm{SCR}^{2} \mathrm{Mega}$ REU/RET site that involves nearly all IEC members and Kemi leads a new IUSE program to expand ECP beyond ECE. The long-term plan is to implement both formal professional development and a red team process for internal proposal review.

- Work with industry to utilize professional development based on best practices from industry. The July 2019 Workshop included a panel session in which industry perspectives on how to improve communication were presented. Key industry partner Intel is driving this effort. Others are expected to join in future workshops.

- Develop new collaborative proposals addressing issues such as broadening participation and implementing design across the curriculum.

- Develop strategies for IEC financial support - IEC Leadership

A post-workshop survey was used to determine what the participants thought of the workshop and what they thought the highest priorities are moving forward. Satisfaction was very high for all sessions and the overall workshop. Using a Likert scale where 1 was strongly agree and 5 was strongly disagree, responses were between 1 and 2 for topics being interesting, relevant, useful, etc. The one area with slightly less agreement was that the tasks and timelines that came out of each session were sufficiently aggressive. This and a universal willingness to work on multiple tasks were very encouraging.

Barriers to Success: For IEC to make progress toward its vision, it is necessary to fully understand the significant barriers to success faced by students and faculty at MSIs. Immediately after the 


\section{The Inclusive Engineering Consortium}

workshop, two groups of IEC professors were tasked to compile lists of the barriers from the student and faculty points-of-view, respectively. The two lists were discussed at the IEC online meeting in October.

Student Barriers

- Lack of confidence (Imposter Syndrome)

- Insufficient pre-college preparation and minimal hands-on exposure and practice

- Financial and few technical student jobs on campus

- Time management

- Infrastructure

- Personal connections (identity)

Faculty Barriers

- Financial (low salaries, small startup packages, lack of new funds)

- Minimal facilities

- Lack of mentors and professional development programs

- Lack of incentives and rewards

- High teaching load, large classes, lack of time to restructure courses

- High service, especially advising, load

- Lack of research tradition and discouragement of educational research

\subsection{Conclusion}

To enhance our degree programs and to improve the overall learning and working experience for students, staff and faculty, we are advancing the creation of a virtual department. This department consists of the entire IEC membership's faculty. We believe that this will result in enhanced efficiency and effectiveness, allowing us to both serve our students better and achieve greater research results. A persistent challenge for smaller departments is the creation, collection and analysis of assessment data as part of continuous program improvement. We believe that this virtual department will also help us to create more effective assessment systems as part of our continuous improvement efforts. We further believe that this consortium will allow us to be competitive in larger, multi-campus research funding opportunities. IEC will enhance technical research in ways our individual departments cannot. For example, we have plans for shared research infrastructure that can be the nexus for even greater research productivity. At present, regular collaborative meetings continue, both in-person and online; new research groups are being formed, consisting of all IEC members and jointly with R1 universities and other Consortia; and IEC support infrastructure is being methodically built up.

\subsection{References}

National Research Council. 2015. Enhancing the Effectiveness of Team Science. Washington, DC: The National Academies Press. https://doi.org/10.17226/19007 


\section{The Inclusive Engineering Consortium}

National Academies of Sciences, Engineering, and Medicine. 2017. A New Vision for Center-Based Engineering Research. Washington, DC: The National Academies Press. https://doi.org/10.17226/24767

National Research Council. (2015). Enhancing the Effectiveness of Team Science. Committee on the Science of Team Science, N.J. Cooke and M. L. Hinton, Editors. Board on Behavioral, Cognative, and Sensory Sciences, Division of Bhavioral and Social Sciences and Education. Washington, DC: The National Academies Press.

K. C. Wooten, R. M. Rose, G. V. Ostir, W. J. Calhoun, B. T. Ameredes, A. R. Brasier, 'Assessing and Evaluating Multidisciplinary Translational Teams: A Mixed Methods Approach,' Evaluation \& the Health Professions 2014, Vol. 37(1) [33-49]

Scott, C. J., \& Aybar, J. D., \& Abraham, S., \& Albin, S., \& Andrei, P., \& Attia, J. O., \& Chouikha, M. F., \& Bernadin, S. L., \& Connor, K. A., \& Dabipi, I. K., \& Eldek, A. A., \& Geddis, D., \& James-Okeke, P. A., \& Kelly, J. C., \& Leigh-Mack, P., \& Morales, J. C., \& Ndoye, M., \& Nyarko, K., \& Oni, B. O., \& Quinones, S. A., \& Reece, M. A., \& Zhang, L., \& Zein-Sabatto, S. (2019, June), Board 65: Work in Progress: Growing and Sustaining a Successful Collaboration of Programs Developing and Implementing Experimental Centric Pedagogy Paper presented at 2019 ASEE Annual Conference \& Exposition, Tampa, Florida. https://peer.asee.org/32399

Connor, K., Scott, C., Chouikha, M., Wilson, A., Anderson, A., Astatke, Y., Berry, F., Newman, D., O’Rourke, J., Little, T., Millard, D. Multi-Institutional Development of Mobile Studio Based Education and Outreach, ASEE Annual Conference, Vancouver, June 2011. https://peer.asee.org/18549

K. Connor, Y. Astatke, C. Kim, A. Eldek, H. Majlesein, P. Andrei, J. Attia, K. Gullie, C. Graves, A. Osareh, "Simultaneous Implementation of Experimental Centric Pedagogy in 13 ECE Programs," ASEE Annual Conference Seattle, WA, June 2015

Astatke, Y., Ladeji-Osias, J., James, P., Moazzami, F., Scott, C., Connor, K., Saka, A., Improving and Expanding Engineering Education in the Middle East and Africa Using Mobile Learning Technology and Innovative Pedagogy in Advances in Engineering Education in the Middle East and Africa, Current Status, and Future Insights, Abdulwahed, M., Hasna, M., Froyd, J., Ed (2016)

K. Connor, D. Newman, K. Gullie, Y. Astatke, C. Kim, J. Attia, P. Andrei, M. Ndoye, "The Implementation of Experiment Centric Pedagogy in 13 ECE Programs - The View from Students and Faculty," ASEE Annual Conference, New Orleans, June 2016

K. Connor, J, Kelly, M. Chouikha, Y. Astatke, P. Andrei, M. Ndoye, A. Eldek, J. Attia, D. Newman, K. Gullie, A. Osareh, L. Hobson, "Matched Assessment Data 


\section{The Inclusive Engineering Consortium}

Set for Experiment Centric Pedagogy Implementation in 13 HBCU ECE Programs," ASEE Annual Conference, Columbus, June 2017

Kenneth A. Connor, Kathy Ann Gullie Ph.D., Dianna Newman, Mohamed F. Chouikha, John D. Kelly, Craig J. Scott, Mandoye Ndoye, Ibibia K. Dabipi, Corey A. Graves, Lei Zhang, Ali Reza Osareh, Sacharia Albin, Demetris Geddis, Petru Andrei, Fred Lacy, Hamid R. Majlesein, Abdelnasser A. Eldek, John Okyere Attia P.E., Yacob Astatke, Shujun Yang, Li Jiang, Ben O. Oni, and Saleh Zein-Sabatto. "Board 26: Experiment-Centric Pedagogy - Improving the HBCU Engineering Student Learning Experience". 2018 ASEE Annual Conference \&amp; Exposition, Salt Lake City, Utah, , June 2018 https://peer.asee.org/29993 